\section{Processes controlling the flux of legacy phosphorus to surface waters at the farm scale}

\author{
VICTORIA BARCALA ${ }^{1}$, JOACHIM ROZEMEIJER ${ }^{1}$, \\ LEONARD OSTÉ ${ }^{1}$, BAS VAN DER GRIFT ${ }^{2}$, LAURENS \\ GERNER $^{3}$ AND THILO BEHRENDS ${ }^{4}$
}

${ }^{1}$ Deltares

${ }^{2}$ KWR Water Research Institute

${ }^{3}$ Water Board Rijn and IJssel

${ }^{4}$ Utrecht University

Presenting Author: victoria.barcalapaolillo@deltares.nl

Phosphorus (P) leaching from agriculture is a major driver of water eutrophication in downstream rivers and lakes. In NW Europe, agriculture intensified after the second world war and recently $\mathrm{P}$ surplus is close to zero [1][2](Figure 1). In drained lowland areas with intensive agriculture, a reduction in the fertilizer applications may be insufficient to improve the water quality in the short term [3], as the $\mathrm{P}$ accumulated in the soil during decades of high fertilization may continue leaching for many years. A complementary approach to reduce $\mathrm{P}$ exports from agriculture are edge-of-field mitigation measures at the farm scale. The selection of effective measures requires a detailed insight into the chemical and hydrological transport mechanisms. We determined the main $\mathrm{P}$ sources, processes, and transport routes at the farm scale to support the selection of appropriate mitigation measures. We quantified the legacy $\mathrm{P}$, the different $\mathrm{P}$ pools in the upper soil, and related it to the yearly $\mathrm{P}$ export downstream. To do this, we combined high-resolution monitoring data from the soil, groundwater, surface water, and ditch sediments. The legacy $\mathrm{P}$ in the topsoil was high, about $2,500 \mathrm{~kg} / \mathrm{ha}$. The predominant subsurface flow and the subsoils' $\mathrm{P}$ sorption capacity retained the $\mathrm{P}$ mobilized from the topsoil and explained the relative moderate flux of $\mathrm{P}$ to surface waters $(0.04$ $\mathrm{kg}$ /ha during the 2018-2019 drainage season). The dissolved $\mathrm{P}$ entering the drainage ditch via groundwater discharge was bound to iron-containing particles formed due to the oxidation of dissolved ferrous iron. Once leached from the soil to the drainage ditch, resuspension of P-rich sediment particles during flow peaks were the most important $\mathrm{P}$ transport mechanism (78\%).

Figure 1 Phosphorus surplus in the Netherlands from 1970 to 2018 [4].

Figure 2 Water and phosphorus balance for the period from 24 December to 16 April 2019.

[1] Bol, R. et al. (2018), Frontiers in Marine Science, 5:276, doi:10.3389/fmars.2018.00276.

[2] McDonald, N. T. et al. (2019) Agriculture, Ecosystems and Environment, 274, doi:10.1016/j.agee.2018.12.014.

[3] Melland, A. R., Fenton, O. and Jordan, P. (2018), Environmental Science and Policy, 84, doi:10.1016/j.envsci.2018.02.011.

[4] CBS (2020) Available at: opendata.cbs.nl/statline/\#/CBS/nl/dataset/83475NED/table? $=1601641484793$.
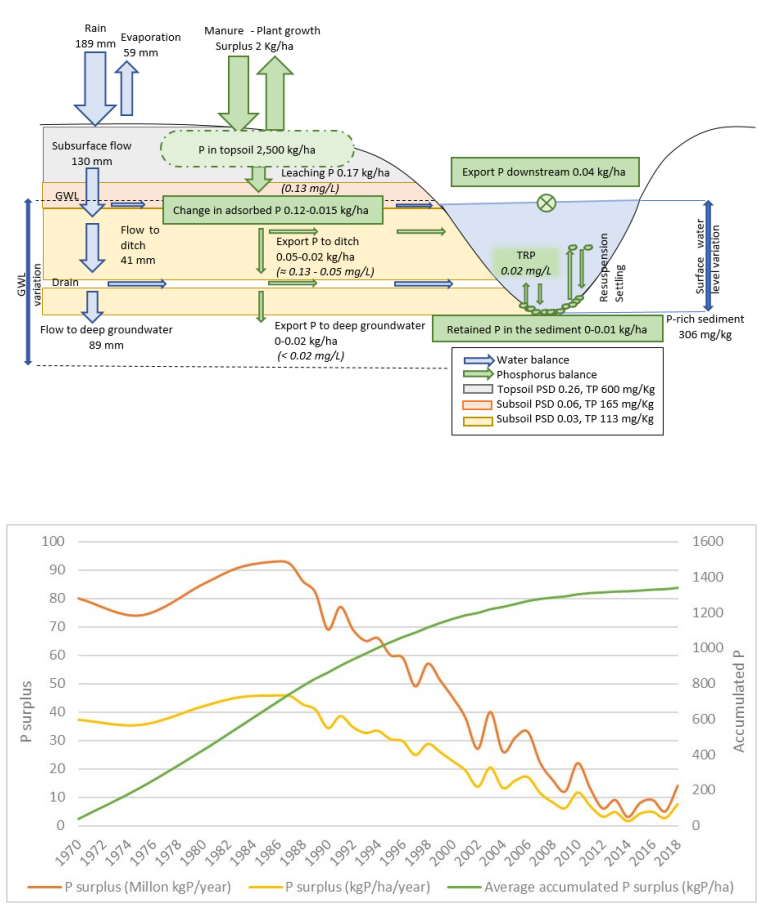